\title{
Estimation of petrol and diesel adulteration with kerosene and assessment of usefulness of selected automobile fuel quality test parameters
}

\author{
${ }^{1}$ Sh. R. Yadav, ${ }^{2 *}$ K. Murthy V, ${ }^{1}$ D. Mishra and ${ }^{1}$ B. Baral \\ ${ }^{1}$ School of Engineering, Department of Mechanical Engineering, Kathmandu University, Dhulikhel, \\ Kavre, Kathmandu, Nepal \\ ${ }^{2}$ School of Science, Department of Biological Sciences and Environmental Science, Kathmandu University, Dhulikhel, \\ Kavre, Kathmandu, Nepal
}

\begin{abstract}
Kerosene is common adulterant utilized for mixing with diesel. Five fuel-adulterant mixtures in different proportions by volume were prepared and individually tested for density and kinematic viscosity. The mixtures were administered to six light cargo vehicles and the tail pipe exhaust emission was tested for opacity value. No appreciable density variation at different levels of adulteration was observed. Density was within the prescribed value even at higher adulteration. Considerable decrease in kinematic viscosity, a departure from prescribed viscosity, was noted at higher adulteration level. The percent opacity value decreased sharply even at small level of adulteration. The probable amount of kerosene present as an adulterant in diesel dispensed at filling stations in Kathmandu city ranged between $35 \%$ and $50 \%$. The observations suggest density test is not a good indicator of diesel adulteration. Kinematic viscosity and opacity value are useful diesel adulteration test parameters. Existing diesel adulteration warrants initiation of strict compliance regulation.
\end{abstract}

Key words: Diesel, adulteration, density, kinematic viscosity, opacity

*Corresponding Author, E-mail: vkm@ku.edu.np

\section{Introduction}

The urban metropolis growth is associated with increasing number of automobiles to meet chiefly public conveyance and goods transport. Kathmandu city is no exception to this phenomenon.

The vehicle models on road range from old to the recent and their traffic is a source among others to urban air pollution. Automobile fuel adulteration is a clandestine and profit oriented operation. Adulteration of diesel by mixing kerosene is a common and widespread practice.

Many vehicles seldom maintained properly run on adulterated fuels. An assessment of the extent of emission, represented by opacity value and fuel quality tests with varied composition of fuel (diesel) and adulterant (kerosene) proportions in diesel was the focus of the study.

The objectives of the study were to assess the of usefulness of density and kinematic viscosity tests applied to different proportional mixtures of fuel and adulterant and also to assess variation in opacity value (k-value) of emission from combustion of adulterated diesel (kerosene in diesel) consequent to the extent of adulteration.

\section{Material and Methods \\ Procurement of pure diesel}

The diesel (32 liters) was procured from army petrol filling station. The purity was ensured by testing density and kinematic viscosity and comparing the values obtained with respective prescribed values. The adulterant used was kerosene (26 liters) procured from a local petrol pump source.

\section{Preparation of custom proportions mixture of fuel and adulterant}

Diesel and kerosene was mixed in volume by volume in six different proportions (100:0, 85:15, 75:25, 65:35, 50:50 and 25:75; volume by volume mixture preparation). The final volume of the prepared fuel-adulterant mixture was 8 liters and this mixture was subjected for testing emissions separately for percent opacity value (k-value).

\section{Laboratory tests}

The Laboratory tests conducted were density and kinematic viscosity. Calibrated hydrometers and thermometers were used for density estimation and American Society for Testing Materials (ASTM, 
1953) chart was used to convert the observed density to density at $15^{\circ} \mathrm{C}$. The kinematic viscosity of diesel was estimated by using ' $U$ ' type calibrated viscometer and the time to be recorded for viscosity testing was noted with help of calibrated stopwatch.

\section{Prerequisite vehicle maintenance work and emission test}

Six diesel run cargo loading vehicles (Make: M/ s. Tata Mobiles, Model 207) manufactured between the years of 1998 to 2000 were selected for the tests. The air cleaner filter, oil filter, engine oil were replaced and the setting of valve clearance and the ignition timing was set according to the manufacturer specification. This maintenance work was done for all the six selected vehicles prior to subjecting them to the emission test.

The diesel vehicles emission tester RTM430 opacimeter was used which was suitable for testing compression ignition engines. The opacity value (kvalue) was estimated after administering of each of diesel-kerosene mixture. The requisite conditions to be followed for vehicles to be tested and the specified calibration steps of the emission tester were strictly adhered to as prescribed and specified in the manual of the emission-testing equipment.

\section{Results}

The density tests conducted for different fuel and adulterant mixtures varied between $0.84 \mathrm{~g} / \mathrm{ml}$ to $0.8234 \mathrm{~g} / \mathrm{ml}$ (Table 1). The Kinematic viscosity reading in centistokes at different adulteration levels showed decreasing trend with the increasing level of adulteration. There was a considerable decrease in the kinematic viscosity at higher adulteration levels. Compared to the prescribed viscosity the departure observed was substantial.

The percent opacity value (\% k-value) with respect to the tail pipe exhaust emission decreased sharply even with a small amount of adulterant addition; at $15 \%$ adulteration level the k-value was 85\% (Table 2).

The emission test conducted with existing diesel (that is commercially dispensed at automotive fuel pump stations) indicated $30 \%$ to $50 \%$ kerosene presence in diesel.

\section{Discission and Conclusion}

The tests results of density and kinematic viscosity were compared with corresponding values prescribed as standards by Indian Standard specification for motor gasoline and high speed diesel. The standard prescribed density for diesel fuel is a value-range from 0.82 to $0.86 \mathrm{gm} / \mathrm{dl}$ (Indian Standard, Specification for High Speed Diesel, 2000). The observations from the experiment suggested that density was within the prescribed range immaterial of diesel-adulteration level with kerosene (Table 1). The presence of kerosene did not to alter density of diesel appreciably and hence density test for adulteration with kerosene is not useful. The observed variation in opacity with different proportions of adulterant although not sharp, showed a decreasing trend with increasing adulterant presence in diesel.

Both kinematic viscosity and percent opacity tests therefore are good indicators in the assessment of kerosene adulteration extent. Compared to the density test, kinematic viscosity test was a better indicator for assessment of adulteration level. An intrinsic intensity modulated fiber optic sensor for determining adulteration of petrol and diesel by kerosene is reported (Sukhdev, 1999).

Table 1:Density and kinematic viscosity of diesel fuel and adulterant kerosene at different proportions

\begin{tabular}{|c|c|c|c|}
\hline No. & $\begin{array}{c}\text { Diesel and } \\
\text { Kerosene } \\
\text { Proportions } \\
(\mathrm{v} / \mathrm{v})\end{array}$ & $\begin{array}{c}\text { Density } \\
\text { at } 15^{\circ} \mathrm{C} \\
(\mathrm{g} / \mathrm{ml})\end{array}$ & $\begin{array}{c}\text { Kinematic } \\
\text { Viscosity at } 40 \\
{ }^{\circ} \mathrm{C}(\mathrm{Cst})\end{array}$ \\
\hline 1 & $\begin{array}{c}\text { Pure Diesel } \\
\text { Prescribed }\end{array}$ & 0.8456 & 2.63 \\
2 & $0.82-0.86$ & 2 to 3 \\
3 & Level & 0.8400 & 2.33 \\
4 & $75: 15$ & 0.8390 & 2.16 \\
5 & $65: 35$ & 0.8321 & 1.89 \\
6 & $50: 50$ & 0.8304 & 1.83 \\
7 & $25: 75$ & 0.8234 & 1.5 \\
\hline
\end{tabular}

Table 2: Variation in opacity value (\% k-value) in diesel fuel according to different fuel and adulterant proportions

\begin{tabular}{|c|c|c|}
\hline No. & $\begin{array}{c}\text { Diesel and Kerosene } \\
\text { Proportions } \\
(\mathrm{v} / \mathrm{v})\end{array}$ & $\begin{array}{c}\text { Mean } \\
\text { Opacity } \\
\text { Value } \\
\text { (\% k-value) }\end{array}$ \\
\hline 1 & Pure Diesel & 100 \\
2 & $\begin{array}{c}\text { Existing Diesel } \\
\text { in Fuel Tank }\end{array}$ & 76 \\
3 & $85: 15$ & 85 \\
4 & $75: 25$ & 81 \\
5 & $65: 35$ & 79 \\
6 & $50: 50$ & 72 \\
7 & $25: 75$ & 70 \\
\hline
\end{tabular}


Another study pertains to diesel fuel contamination by excitation emission matrix spectral subtraction fluorescence; it is reported that this method is efficacious in the whole range of $0-90 \% \mathrm{v} /$ $\mathrm{v}$ of various adulterants present in diesel (Digambara, 2001). However, the kinematic viscosity and density tests are considered routine fuel quality test parameters for which prescribed values considered as standard values are available.

An attempt to estimate the extent of adulteration (possibly with kerosene) of the existing diesel in the fuel tank of vehicles in terms of emission of was carried out. The emission prescription of opacity percent value for diesel not mixed with kerosene (pure fuel) was considered as $100 \%$ and a comparison was made to the emissions from the fuel that existed in the vehicles selected and subjected to the emission tests. However, the vehicle maintenance steps were followed before subjecting to emission test. This experiment gave an estimate of extent of adulteration of diesel dispensed at the diesel filling-stations in the city.

The tests indicated a considerable diesel adulteration level, warranting strict compliance and dispensation of fuels of prescribed quality. If neglected, the adulteration level could rise to further higher levels and could be cause for increased ambient air pollution and consequent increased morbidity.

\section{Acknowledgement}

The authors acknowledge express their gratitude and thanks to the support and encouragement extended by Professor Suresh Raj Sharma, Vice Chancellor, Professor Sitaram Adhikary, Registrar and Professor Dinesh Prasad Chapagain, Dean, School of Engineering, Professor Pushpa Raj Adhikary, Dean School of Science, Kathmandu University. The help and cooperation of Nepal Oil Corporation, Valley Traffic Police Department is acknowledged. The financial support extended by the university to conduct the project is gratefully acknowledged.

\section{References}

American Society for Testing Materials, Institute of Petroleum, Portland Place London. Reduction of observed density to density at $15{ }^{\circ} \mathrm{C}$ and volume at 15 ${ }^{\circ} \mathrm{C}$, Copyright Publication, 1953

Indian Oil Corporation, Industry quality control manual, Indian Standard Specification for High Speed

Diesel (HSD) Oil-IS:1460-1995 (Amendment No. 3), 2000

Patra, D. and A. K. Mishra, Study of diesel fuel contamination by excitation emission matrix spectral subtraction fluorescence. Analytica Chimica Acta, 454 (2):209-215, 2001

Sukhdev, R., Fiber optic sensor for determining adulteration of petrol and diesel by kerosene. Science Direct: Sensors and Actuators B: Chemical, 55 (23):212-216, 2002 